\title{
Clinical and Hematological Changes in Childhood Malaria in India
}

\author{
Ritika Chhawchharia ${ }^{1}$, Shital Kolhe ${ }^{2}$, Riya George ${ }^{3}$, Keya R. Lahiri ${ }^{4}$ \\ I'Postgraduate Student, Department Of Pediatrics, D Y Patil Medical College, Navi Mumbai, India) \\ ${ }^{2}$ (Associate Professor, Department Of Pediatrics, D Y Patil Medical College, Navi Mumbai, India) \\ ${ }^{3}$ (Assistant Professor, Department Of Pediatrics, D Y Patil Medical College, Navi Mumbai, India) \\ ${ }^{4}$ (Professor And Head, Department Of Pediatrics, D Y Patil Medical College, Navi Mumbai, India)
}

\begin{abstract}
Malaria caused by Plasmodium species is a disease with high morbidity and mortality, especially in children. The changing clinical and blood manifestations of P.falciparum, emerging trends of complications with P.vivax are some of the important issues that merit attention at present in India. The prospective crosssectional study conducted on 170 patients of malaria in Mumbai aimed at studying the clinico-haematological alterations in the disease. Fever and splenomegaly were critical findings in majority of patients so that they may be used for clinical diagnosis of malaria and early institution of therapy. P.vivax was the predominant species with severe thrombocytopenia however anemia was common in P.falciparum infection.Older children were affected more severely than infants with hematological complications, namely anemia and thrombocytopenia. Anemia and thrombocytopenia were common observations while leucocyte count was normal in most patients. After 48 hours of antimalarial treatment, platelet count improved with restoration to normal in majority of patients while anemia worsened in most cases. There was a negative correlation between platelet count and hyperparasitemia. Despite availability of extensive literature on various manifestations of malaria, the evolving nature of the disease mandates continuous revision of existing data.
\end{abstract}

Keywords: childhood malaria, clinical, hematological

\section{Introduction}

"Malaria" derived its name from the Italian language (mala - bad; aria - air) as it was believed to be caused by foul air near marshy areas.Malaria is a global health problem,imposing the biggest socio-economic burdens on humanity. Despite the early success of malaria eradication programme in 1950-60, there was an upsurge of cases in 1970s when the disease cameback with a vengeance. New malaria ecotypes developed from environmental impact and were followed by epidemics in the 1990s [1]. At present, official figures for malaria in Indiaindicate 0.7-1.6 million confirmed cases and 400-1,000 deaths annually[2].

According to the World Malaria Report 2014, 22\% of Indian population live in high transmission (> 1 case per 1000 population) areas, $67 \%$ live in low transmission (0-1 cases per 1000 population) areas and $11 \%$ live in malaria-free areas. In 2013, 0.88 million cases have been recorded, with P.falciparum causing 53\% and P.vivax causing $47 \%$ of the infections [3].

Haematological alterations like anemia, qualitative and quantitative changes in platelets, leukocytosis or leucopenia are well known in malaria. Most of these findings are more pronounced in P.falciparum as compared to P.vivax. However, there is no unanimity in the findings with some studies showing minimal differences and others showing significant haematological alteration in P.falciparum as compared to P.vivax.

Clinical diagnosis of malaria is important especially in the tropical countries due to lack of credible diagnostic facilities and scarce health care in these areas. Timely upgradation of previous data is necessary to be adept with the course of the disease to facilitate early diagnosis and prompt treatment.

\section{Methods and Materials}

A prospective cross-sectional study was conducted in a tertiary care centre for a total duration of 2 years, including inpatients of age $<12$ years, with P.vivax or P.falciparum malaria, confirmed on peripheral smear examination or a positive rapid malaria antigen test. Patients $>12$ years or who had received empirical therapy with anti-malarials were excluded from the study. A self-constructed semi-structured case record form was used to record the clinical features, and laboratory parameters like complete hemogram, peripheral smear and rapid antigen test for malaria. Daily hemograms were recorded after initiation of therapy with anti-malarial drugs, as per WHO guidelines 2010. Institutional ethics committee approval was taken and an informed consent was obtained before enrolling patients for the study. 
Data was collected from 170 patients and statistical analysis was done using SPSS software (version 22). Data was analysed using the chi-square test, Spearman's Rho Correlation ratio and z-test of proportion. A $p$ value $<0.05$ was considered statistically significant.

Hemoglobin $<10 \mathrm{gm} \%$ was considered as anemia and those with $<5 \mathrm{gm} \%$ were considered severely anemic. Total white blood cell (WBC) count between 5,000-16,000cells/cu.mm was considered normal. Platelet count less than 1,50,000 was considered thrombocytopenia, which was divided into mild $(1,00,000-1,50,000$ cells/cu.mm), moderate $(50,000-1,00,000$ cells/cu.mm.) and severe categories $(<50,000$ cells/cu.mm $)$. Restoration of platelet count to $>1,50,000$ cells/cu.mm was considered end point in serial hemograms.

\section{Results}

Our study consisted of 170 cases, with $57.6 \%$ males and $42.4 \%$ females. P.vivax was the predominant species causing malaria in $69.4 \%$ cases while only $9.4 \%$ cases had P.falciparum malaria. Mixed infections with P.falciparum and P.vivax were found in $21.2 \%$ cases. Malaria was commoner in older children $(41.8 \%, 46.2 \%$ of 1-5 years and $>5$ years age group respectively) as compared to $11.9 \%$ of infants, which is also a sizeable amount.

Fever was a universal finding with vomiting second in line, observed in $38.2 \%$ patients, followed by abdominal pain, nausea and headache. Convulsions and altered sensorium were seen in $10.5 \%$ and $5.2 \%$ patients, respectively. There were no patients with bleeding manifestations, despite thrombocytopenia. Hepatomegaly and splenomegaly were common, as observed in $78.3 \%$ and $95.2 \%$ of cases.

\section{Hematological Profile of Malaria}

Anemia with mean hemoglobin of $9.54 \mathrm{gm} / \mathrm{dL}$ was a common finding. Mean leucocyte count and platelet count were $7.15 \times 10^{3}$ and $110 \times 10^{3}$ respectively. Mean hemoglobin, leucocyte count and platelet count in different age groups are shown in (Table 1), which suggests that infants were more anemic as compared to older children while thrombocytopenia was commoner in older children. Leucocyte count was normal in majority of cases. Mean hemoglobin was lowest in children with P.falciparum malaria while thrombocytopenia was observed in mixed malaria more often than P.falciparum or P.vivax malaria alone. (Table 2)

\section{Anemia in Malaria}

Anemia was a common manifestation of malaria, observed in $54.1 \%$ cases, out of which, $2.9 \%$ cases suffered from severe anemia. Infants and children between 1-5 years were highly susceptible to develop anemia, constituting $80 \%$ and $67.6 \%$ of cases in each group respectively $(\mathbf{p}<\mathbf{0 . 0 5})$. Anemia was found to be associated with $50.8 \%$ of P.vivax cases, $56.3 \%$ of P.falciparum and $63.8 \%$ of mixed malaria cases(Table 3). A negative correlation was observed between hemoglobin and duration of fever, and hemoglobin and hyperparasitemia; however, these results did not reach statistical significance. After 48 hours of treatment with anti-malarial drugs, a further drop in hemoglobin was observed in $54.7 \%$ of cases.

\section{Leucocyte Counts in Malaria}

Majority of patients had a normal leucocyte count while $42.9 \%$ cases demonstrated leucopenia.

\section{Thrombocytopenia in Malaria}

Thrombocytopenia was observed in $74.2 \%$ cases, and $12.9 \%$ cases had severe thrombocytopenia. Thrombocytopenia was more rampant in older children with $78.9 \%$ of $1-5$ year olds and $70.9 \%$ of $>5$ year olds affected with it. P.vivax, P.falciparum and mixed infections were responsible for thrombocytopenia in $71.1 \%$, $68.7 \%$ and $86.1 \%$ cases respectively. Proportion of severe, moderate and mild thrombocytopenia was significantly higher in P.vivax infection than P.falciparum or mixed infection $(\mathrm{p}<0.05)($ Table 4$)$. A negative correlation was observed between platelet count and hyperparasitemia, measured by parasitic index on peripheral smears $(\mathrm{p}<0.05)$. Platelet count and duration of fever prior to treatment were also studied and a negative correlation was found. Majority of patients $(89.5 \%)$ responded well to anti-malarial treatment in terms of rise in platelet count after 48 hours of treatment. Remaining $10.5 \%$ patients with thrombocytopenia showed a further fall in platelet count, however, the counts were recovered by the end of treatment. Normal platelet count i.e., >1,50,000 cells/cu.mm was restored within 48 hours of treatment in 51/104 patents. Only one patient required 7 days while 10 patients restored normal platelet count within 24 hours.

\section{DISCUSSION}

Malaria poses a significant health burden in India, with its widespread upsurge in rural as well as urban areas. In spite of various eradicative measures taken around the world, it remains the most notorious protozoal infection amongst humans. Hematological changes are the hallmark of malaria and their meticulous analysis can be instrumental in prompt and accurate diagnosis of the disease. 
In this study, $69.4 \%$ cases were P.vivax, followed by $21.9 \%$ mixed and $9.4 \%$ P.falciparum infection. It can be proposed that P.vivax cases are on a rising trend amongst children with greater morbidities $(4,5,6)$. Under-fives were more affected than infants in this study, which is in accordance with previous explanations that, fetal hemoglobin and maternal IgG confer immunity to infants $(7,8)$. However, as many as $11.9 \%$ of affected infants is afine example of poor disease control and changing epidemiology of malaria.

Fever has been described as one of the cardinal symptoms in malaria and is of historical importance. Other common symptoms observed were vomiting, pain in abdomen, headache, and nausea. None of the cases presented with bleeding manifestations, despite thrombocytopenia. . Expression of tissue factor (TF) on the endothelium, and pro-coagulant role of parasitized RBC and activated platelets can explain absence of bleeding manifestation in malaria (9). Complications like ARDS, cerebral malaria and prerenal shutdown were observed more with P.vivax. This perspective is alarming while considering drug resistance in malaria.

Splenomegaly was described as a characteristic feature, by Hippocrates in the $5^{\text {th }}$ century BC(10). Splenomegaly was a critical diagnostic feature in our study. With the above observations, it can be safely inferred that fever with splenomegaly in a child should compel us to strongly suspect malaria.

Anemia is a common feature of malaria, as exemplified by mean hemoglobin level of $9.54 \mathrm{~g} / \mathrm{dL}$ in our study and similar values in a study from Kenya and Karnataka $(11,4)$. Out of the $54.1 \%$ cases with anemia, $2.9 \%$ cases of severe malaria indicate high morbidity of the disease. In the developing countries, nutritional deficiencies and parasitic infestations aggravate anemia leading to dimorphic patterns (12). Under-fives are more prone to develop anemia, which can be explained by the smaller red cell mass and relatively lower immunity to malarial parasite as opposed to older children who acquire immunity due to repeated exposure to the parasite (13). Severe anemia was observed in patients with longer duration of fever and hyperparasitemia. Even after receiving treatment for 48 hours, $54.7 \%$ patients demonstrated a further fall in hemoglobin. This observation is also reported by Price et al and Das et al in their studies $(14,15)$. Malaria causes dyserythropoeisis and depressed reticulocytosis, along with increased destruction of parasitized and unparasitized erythrocytes thatcauses a slow recovery even after decreased parasitemia (16). Early treatment with antimalarials can truncate the impending anemia and accelerate recovery (17). Hyperparasitemia is associated with increased risk of anemia in malaria $(11,12,18,19)$.

Although mean leucocyte count was normal, leucopenia was observed in $42.9 \%$ of cases. This observation is supported by other studies that have demonstrated leucopenia $(17,20,21)$ and in contrast with another study that have demonstrated leukocytosis (11).

Thrombocytopenia is a consistent finding in both P.vivax and P.falciparum malaria in various studies conducted all over the world $(5,11,22,23,24)$. Around $74.2 \%$ of cases in our study had thrombocytopenia which was also observed in various studies conducted in Thailand, USA and Australia $(17,25,26)$. Children more than 5 years weresusceptible to thrombocytopenia as also demonstrated in another study by Ladhani et al (27). Although thrombocytopenia was rampant amongst cases of P.vivax malaria, severe thrombocytopenia was seen in P.falciparum cases. Over the years, more studies report increasing incidence of thrombocytopenia with P.vivax malaria (4,28). More the parasitemia more was the occurrence of thrombocytopenia in our study. Rojansthein et al and Horstmann et al also presented similar results in their respective studies(29,30). Complete recovery of thrombocytopenia occurred rapidly within 48-72 hours without any bleeding manifestationsin majority of cases and only one patient required 7 days. Joshi et al in India obtained similar result in their study with 92 patients(31).

\section{Figures and Tables}

Figure 1: Clinical features of malaria: Fever was a universal finding present in $100 \%$ cases. Bleeding manifestations were not observed in any patient despite thrombocytopenia.

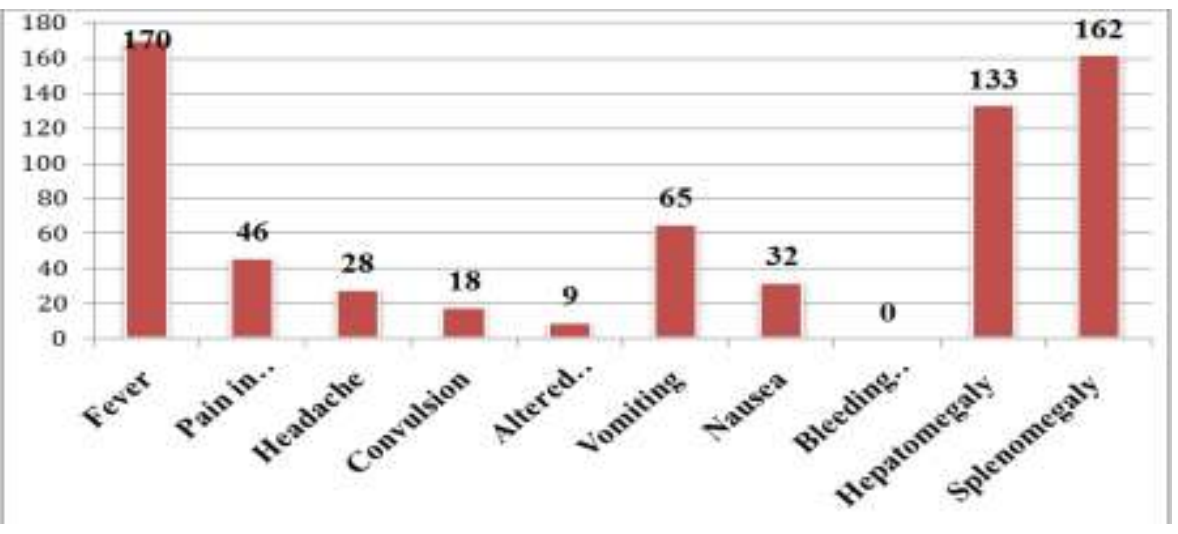


Table 1: Mean hemoglobin, leucocyte and platelet counts in different age groups- Anemia, thrombocytopenia were common findings with infants being more susceptible to anemia.

\begin{tabular}{|l|l|l|l|}
\hline AGE GROUPS & HEMOGLOBIN $(\mathrm{g} / \mathbf{d L})$ & TLC $($ cells/cu.mm.) & PLATELETS(cells/cu.mm.) \\
\hline & Mean & Mean & Mean \\
\hline $0-1$ years & 8.52 & $7.88 \times 10^{3}$ & $124 \times 10^{3}$ \\
\hline $1-5$ years & 9.14 & $7.79 \times 10^{3}$ & $108 \times 10^{3}$ \\
\hline More than 5 years & 10.07 & $6.51 \times 10^{3}$ & $107 \times 10^{3}$ \\
\hline
\end{tabular}

Table 2: Mean hemoglobin, leucocyte and platelet counts in different Plasmodium species - Anemia was more common with P.falciparum infection while mixed infections were more prone to thrombocytopenia

\begin{tabular}{|l|l|l|l|l|}
\hline & & HEMOGLOBIN $(\mathrm{g} / \mathrm{dL})$ & TLC $($ cells/cu.mm.) & $\begin{array}{l}\text { PLATELETS } \\
\text { (cells/cu.mm.) }\end{array}$ \\
\hline & & Mean & Mean & Mean \\
\hline \multirow{3}{*}{ Parasite } & Mixed Malaria & 9.19 & $7.84 \times 10^{3}$ & $85 \times 10^{3}$ \\
\cline { 2 - 6 } & Plasmodium falciparum & 8.92 & $7.94 \times 10^{3}$ & $117 \times 10^{3}$ \\
\cline { 2 - 5 } & Plasmodium vivax & 9.72 & $6.84 \times 10^{3}$ & $116 \times 10^{3}$ \\
\hline
\end{tabular}

Table 3: Distribution of Anemia in different age groups and species of Plasmodium- Infants and falciparum malaria were more severely affected with anemia.

\begin{tabular}{|c|c|c|c|c|c|c|}
\hline & \multicolumn{3}{|c|}{ Age group } & \multicolumn{3}{|l|}{ Species } \\
\hline & $0-1$ yrs & $1-5 \mathrm{yrs}$ & $>5 \mathrm{yrs}$ & P. vivax & P. falciparum & Mixed \\
\hline Severe anemia $(<5 \mathrm{~g} \%)$ & $\begin{array}{l}1 \\
(5.0 \%)\end{array}$ & $\begin{array}{l}1 \\
(1.4 \%)\end{array}$ & $\begin{array}{l}3 \\
(3.8 \%)\end{array}$ & $\begin{array}{l}1 \\
(0.8 \%)\end{array}$ & $\begin{array}{l}2 \\
(12.6 \%)\end{array}$ & $\begin{array}{l}2 \\
(5.5 \%)\end{array}$ \\
\hline Anemia $(5-10 \mathrm{~g} \%$ & $\begin{array}{l}15 \\
(75.0 \%)\end{array}$ & \begin{tabular}{|l}
47 \\
$(66.2 \%)$
\end{tabular} & $\begin{array}{l}25 \\
(31.6 \%)\end{array}$ & \begin{tabular}{|l}
59 \\
$(50.0 \%)$
\end{tabular} & \begin{tabular}{|l}
7 \\
$(43.7 \%)$
\end{tabular} & $\begin{array}{l}21 \\
(58.3 \%)\end{array}$ \\
\hline Normal $(>10 \mathrm{~g} \%)$ & $\begin{array}{l}4 \\
(20.0 \%)\end{array}$ & $\begin{array}{l}23 \\
(32.4 \% 0\end{array}$ & \begin{tabular}{|l}
51 \\
$(64.5 \%)$
\end{tabular} & \begin{tabular}{|l}
58 \\
$(49.2 \%)$
\end{tabular} & $\begin{array}{l}7 \\
(43.7 \%)\end{array}$ & $\begin{array}{l}13 \\
(36.2 \%)\end{array}$ \\
\hline Total & $\begin{array}{l}20 \\
(100 \%)\end{array}$ & $\begin{array}{l}71 \\
(100 \%)\end{array}$ & $\begin{array}{l}79 \\
(100 \%)\end{array}$ & $\begin{array}{l}118 \\
(100 \%)\end{array}$ & $\begin{array}{l}16 \\
(100 \%)\end{array}$ & $\begin{array}{l}36 \\
(100 \%)\end{array}$ \\
\hline
\end{tabular}

Table 4: Distribution of Thrombocytopenia in different age groups and species of Plasmodium - Older children 1-5 years and mixed malaria cases were more severely affected with thrombocytopenia.

\begin{tabular}{|l|l|l|l|l|l|l|}
\hline Thrombocytopenia & $\mathbf{0}-\mathbf{1}$ years & $\begin{array}{l}\mathbf{1}-\mathbf{5} \\
\text { years }\end{array}$ & $\mathbf{> 5}$ years & P vivax & P.falciparum & Mixed \\
\hline \multirow{2}{*}{ Severe } & 2 & 16 & 20 & 22 & 7 & 9 \\
& $10.0 \%$ & $22.5 \%$ & $25.4 \%$ & $18.6 \%$ & $43.7 \%$ & $25 \%$ \\
\hline \multirow{2}{*}{ Moderate } & 10 & 31 & 25 & 47 & 1 & 18 \\
& $50.0 \%$ & $44.7 \%$ & $31.6 \%$ & $39.8 \%$ & $6.3 \%$ & $50 \%$ \\
\hline \multirow{2}{*}{ Mild } & 2 & 9 & 11 & 15 & 3 & 4 \\
& $10.0 \%$ & $12.7 \%$ & $13.9 \%$ & $12.7 \%$ & $18.8 \%$ & $11.2 \%$ \\
\hline \multirow{2}{*}{ Normal } & 6 & 15 & 23 & 34 & 5 & 5 \\
& $30.0 \%$ & $21.1 \%$ & $29.1 \%$ & $28.9 \%$ & $31.2 \%$ & $13.8 \%$ \\
\hline \multirow{2}{*}{ Total } & 20 & 71 & 79 & 118 & 16 & 36 \\
& $100 \%$ & $100 \%$ & $100 \%$ & $100 \%$ & $100 \%$ & $100 \%$ \\
\hline
\end{tabular}

\section{Conclusions}

Infection with P.vivax is on a rise with increasing morbidities even in infants. Fever with chills and splenomegaly are significant clinical indicators for suspecting malaria. Anemia and thrombocytopenia are common manifestations with little effect on leucocyte count. As against previous knowledge, P.vivax is emerging out as an equally notorious parasite, if not more than P.falciparum. Morbidity in terms of thrombocytopenia and anemia are related to hyperparasitemia. With treatment, anemia tends to worsen initially. This study alerts us towards the increasing occurrence of complicated malarias in different age groups and with different species.

\section{Acknowledgements}

We are grateful to the pathology department of D Y Patil Medical College for providing us lab support. We also thank Mr Sakharam for assisting with statistical analysis. 


\section{References}

[1]. Das NG, Baruah I, Kamal S, Sarkar PK, Das SC, Santhanam K. An epidemiological and Entomological investigation on malaria outbreak at Tamalpur PHC, Assam. Indian J Malariol. 1997;34:164-170

[2]. Malaria situation. National Vector Borne Disease control Programme. Available at http://nvbdcp.gov.in/Doc/mal-situationJuly15.pdf

[3]. WHO. World Malaria Report 2014. WHO, Geneva. $2014 . \quad$ Available http://apps.who.int/iris/bitstream/10665/144852/2/9789241564830_eng.pdf

[4]. Kochar, Dhanpat Kumar, et al.Clinical features of children hospitalised with malaria- a study from Bikaner, North West India. The Am J Trop Med Hyg. 2010;83.5:981-989

[5]. Shetty G., Avabratha SK, Gonsalves S., Dany A, Rai SB. Thrombocytopenia in children with malaria-A study from coastal Karnataka, India. Asian Pacific Journal of Tropical Disease (2012)107-109

[6]. Gupta NK, Bansal SB, Jain UC, Sahare K. Study of thrombocytopenia in patients of malaria. Trop Parasitol 2013;3:58-61.

[7]. Amaratunga C, Lopera-Mesa TM, Brittain NJ, Cholera R, Arie T, et al. (2011) A Role for Fetal Hemoglobin and Maternal Immune IgG in Infant Resistance to Plasmodium falciparum Malaria. PLoS ONE 6(4): e14798. doi:10.1371/journal.pone.0014798

[8]. Okiro EA, Taiar AA, Reyburn H, Idro R, Berkley JA, Snow RW. Age patterns of severe pediatric malaria and their relationship to Plasmodium falciparum transmission intensity. Malaria Journal.2009;8:4.

[9]. Ivo M. B. Francischetti IMB., Seydel KB., Monteiro RQ. Blood Coagulation, Inflammation and Malaria. Microcirculation. 2008 February; 15(2): 81-107. doi: 10.1080/10739680701451516

[10]. Hippocrates: On Airs, Waters, and Places. 400 BCE. London: Sydenham Society; 1849::179-222. [The Internet Classics Archive 1994; Book 2, Part 7. English translation: Adams F. The Genuine Works of Hippocrates]

[11]. Maina RN,Walsh D., Gaddy C., Hongo G., Waitumbi J., Otieno L.,Jones D., Ogutu BR. Impact of Plasmodium falciparum infection on haematological parameters in children living in Western Kenya. Malaria Journal December 2010, 9:S4, DOI 10.1186/14752875-9-S3-S4

[12]. Ghosh K. Pathogenesis of anaemia in malaria, a concise review Parasitol Res. 2007; 101:1463- 1469.

[13]. Newton CR, Krishna S. Severe falciparum malaria in children. Current understanding of pathophysiology and supportive treatment. Pharmacol Ther 1998; 79: 1-53.

[14]. Price RN, Simpson JA, Nosten F, Luxemburger C, Hkirijaroen L, ter Kuile F, Chongsuphajaisiddhi T, White NJ: Factors contributing to anemia after uncomplicated falciparum malaria. Am J Trop Med Hyg 2001, 65:614-622.

[15]. Das BS, Nanda NK, Rath PK, Satapathy RN, Das DB. Anaemia in acute, Plasmodium falciparum malaria in children from Orissa state, India. Ann Trop Med Parasitol. 1999 Mar;93(2):109-18.

[16]. Looareesuwan S, Merry AH, Phillips RE, Pleehachinda R, Wattanagoon Y, Ho M, Charoenlarp P, Warrell DA, Weatherall DJ, 1987. Reduced erythrocyte survival following clearance of malarial parasitemia in Thai patients. Br J Haematol 67: 473-478

[17]. Erhart LM, Yingyuen K, Chuanak N, et al. Hematological and clinical indices of malaria in a semi-immune population of western Thailand. Am J Trop Med Hyg 2004; 70:8-14.

[18]. Ayodotun Olutola and Olugbenga Mokuolu (2012). Severe Malaria Anaemia in Children, Anemia, Dr. Donald Silverberg (Ed.), ISBN: 978-953-51-0138-3, InTech, Available from: http://www.intechopen.com/books/anemia/severe-malaria-anaemia-in-children

[19]. Kathryn N. Suh, Kevin C. Kain, Jay S. Keystone. Malaria. CMAJ. 2004 May 25; 170(11): 1693-1702. doi: 10.1503/cmaj.1030418

[20]. Lathia TB, Joshi R: Can hematological parameters discriminate malaria from nonmalarious acute febrile illness in the tropics? Indian J Med Sci 2004, 58:239-244.

[21]. Kotepui M, Phunphuech B, Phiwklam N, Chupeerach C, Duangmano S. Effect of malarial infection on haematological parameters in population near Thailand-Myanmar border. MalariaJournal 2014, 13:218,doi:10.1186/1475-2875-13-218

[22]. Jadhav UM, Patkar VS, Kadam NN. Thrombocytopenia in malaria: Correlation with type and severity of malaria. J Assoc Physicians India. 2004;52:615-8

[23]. Patel A, Jain S, Patel B, Modi B. Hematological Changes in P.Falciparum \& P.Vivax Malaria. Natl J Med Res.

[24]. Tanwar GS, Khatri PC, Chahar CK, Sengar GS, Kochar A, Tanwar G, Chahar S, Khatri N, Middha S, Acharya J, Kochar SK, Pakalapati D, Garg S, Das A, Kochar DK. Thrombocytopenia in childhood malaria with special reference to P. vivax monoinfection: A study from Bikaner (Northwestern India). 2012;23(3):211-6. doi: 10.3109/09537104.2011.607520.

[25]. Kotwal RS, Wenzel RB, Sterling RA, Porter WD, Jordan NN, Petruccelli BP. An outbreak of malaria in US Army rangers returning from Afghanistan. JAMA 2005; 293:212-6.

[26]. ElliottJH, O’BrienD, LederK, etal. Imported Plasmodium vivax malaria: demographic and clinical features in nonimmune travelers. J Travel Med 2004; 11:213-6.

[27]. Ladhani, S., Lowe, B., Cole, A. O., Kowuondo, K. and Newton, C. R. J. C. (2002), Changes in white blood cells and platelets in children with falciparum malaria: relationship to disease outcome. British Journal of Haematology, 119: 839-847. doi: 10.1046/j.1365-2141.2002.03904.X

[28]. Kochar DK, Das A, Kochar A, Middha S, Acharya J, Tanwar GS, Gupta A, Pakalapati D, Garg S, Saxena V, Subudhi AK, Boopathi PA, Sirohi P, Kochar SK. Thrombocytopenia in Plasmodium falciparum, Plasmodium vivax and mixed infection malaria: a study from Bikaner (Northwestern India). Platelets. 2010;21(8):623-7. doi: 10.3109/09537104.2010.505308.

[29]. Rojanasthien S, Surakamolleart V, Boonpucknavig S, Isarangkura P. Hematological and coagulation studies in malaria. J Med Assoc Thai 1992;75 Supl 1:190-194

[30]. Horstmann RD, Dietrich M, Bienzle U, Rasche. H Malaria induced thrombocytopenia. Blut 1981;42:157-64

[31]. Joshi HA, Shah SS. Thrombocytopenia in P. vivax Malaria, National Journal of Integrated Research in Medicine 2012; 3 (2): 125128 . 